\title{
PEMODELAN DAN PERAMALAN INDEKS HARGA SAHAM GABUNGAN (IHSG) MENGGUNAKAN ARIMAX-TARCH
}

\author{
Endah Fauziyah $^{1}$, Dwi Ispriyanti ${ }^{2}$ Tarno $^{3}$ \\ ${ }^{1,2,3}$,Departemen Statistika, Fakultas Sains dan Matematika, Universitas Diponegoro \\ endah.fauziyah49@gmail.com
}

\begin{abstract}
The Composite Stock Price Index (IHSG) is a value that describes the combined performance of all shares listed on the Indonesia Stock Exchange. JCI serves as a benchmark for investors in investing. The method used to predict future conditions based on past data is forecasting . Autoregressive Integrated Moving Average with Exogenous Variables (ARIMAX) is amodel time series that can be used for forecasting. Financial data has high volatility which causes the variance of the residual model which is not constant (heteroscedasticity). ARCH / GARCH model is used to solve the heteroscedasticity problem in the model. If the data is heteroscedastic and asymmetric, then the model can be used Threshold Autoregressive Conditional Heteroskedasticity (TARCH). The data used are the Composite Stock Price Index (IHSG) for the January 2000 - April 2020 period and the dollar exchange rate data for the January 2000 - April 2020 period asvariables independent from the ARIMAX model. The best model used to predict the JCI from the results of this study is the ARIMAX $(1,1,0)$-TARCH $(1,2)$ model with an AIC value of -0.819074 .
\end{abstract}

Keywords: IHSG, forecasting, ARIMAX, TARCH

\section{PENDAHULUAN}

Perkembangan pasar modal di Indonesia sangatlah pesat semenjak pemerintah melakukan regulasi di bidang keuangan dan perbankan termasuk pasar modal. Salah satu indikator yang sering digunakan untuk melihat perkembangan pasar modal Indonesia adalah Indeks Harga Saham Gabungan (IHSG). Dalam suatu pasar modal, IHSG merupakan indikator utama yang menggambarkan pergerakan harga saham di pasar modal, sehingga dapat mempengaruhi trader/investor. Bagi investor salah satu cara untuk menghasilkan keputusan investasi dalam jangka pendek maupun jangka panjang yang tepat, maka perlu dilakukannya peramalan.

Diperlukan model time series dalam melakukan peramalan. Salah satu model time series yang digunakan untuk menganalisis data time series univariat adalah model ARIMA (p,d,q) (Makridakis, 1999). ARIMA adalah model yang hanya menggunakan variabel dependen yang dipengaruhi waktu ke-t, dan disempurnakan oleh metode ARIMAX yang menggunakan tambahan variabel eksogen (variabel independen) yang mempengaruhi variabel dependen (Rosadi, 2012). Pada prakteknya pemodelan ARIMA maupun ARIMAX pada suatu data time series terutama data ekonomi seringkali memberikan residual dengan varian yang tidak konstan (heteroskedastisitas). Untuk mengatasi hal tersebut, maka Engle (1982) memperkenalkan model ARCH (Autoregressive Conditional Heteroscedasticity). Istilah conditional heteroscedasticity atau heteroskedastisitas bersyarat berarti bahwa nilai residual bergantung kepada nilai residual sebelumnya dan dikembangkan Bollerslev (1986) menjadi model GARCH (Generalized Autoregressive Conditional Heteroscedasticity) dengan varian residual tidak hanya bergantung kepada nilai residual periode lalu, tetapi juga dipengaruhi oleh varian residual periode sebelumnya. 
Pada data finansial sering terjadinya keadaan leverage effect, yaitu suatu keadaan dimana kondisi bad news dan good news memberikan pengaruh yang tidak simetris terhadap volatilitasnya, dan model ARCH/GARCH tidak dapat mengatasi pengaruh asimetris. untuk pengaruh asimetris dapat digunakan model Threshold Autoregressive Conditional Heteroskedastic (TARCH) (Zakoian, 1993).

\section{TINJAUAN PUSTAKA}

\subsection{Stasioneritas}

Menurut Wei (2006), terdapat dua macam stasioneritas, yaitu:

1. Stasioner dalam varian

Suatu data time series dikatakan stasioner dalam varian apabila struktur data dari waktu ke waktu memiliki fluktuasi data yang tetap atau konstan dan tidak berubah-ubah. Untuk mendeteksi ketidakstasioneran dalam varian dapat digunakan plot Box-Cox

2. Stasioner dalam mean

Stasioneritas dalam mean adalah fluktuasi data berada disekitar suatu nilai ratarata yang konstan, tidak tergantung pada waktu dan variansi dari fluktuasi tersebut. Untuk mendeteksi ketidakstasioneran dalam mean dapat dilakukan uji Augmented Dickey Fuller. Uji stasioner dengan Augmented Dickey Fuller (ADF) merupakan pengujian stasioneritas dengan menentukan apakah data time series mengandung akar unit (unit root) atau bersifat nonstasioner (Rusdi, 2011). Pengujian dilakukan dengan menguji hipotesis dalam persamaan berikut:

$$
\Delta y_{t}=\alpha+\delta t+\rho y_{t-1}+\sum_{j=1}^{k} \phi_{j} \Delta y_{t-j}+e_{t}
$$

dengan

$$
\Delta y_{t}=y_{t}-y_{t-1} \operatorname{dan} \rho=a-1
$$

Berdasarkan persamaan (2.1) Uji ADF memiliki hipotesis sebagai berikut Hipotesis :

$H_{0}: \rho=0$ (Terdapat akar unit sehingga data tidak stasioner)

$H_{1}: \rho \neq 0$ (Tidak terdapat akar unit sehingga data stasioner)

Statistik uji :

$t=\frac{\rho}{\operatorname{se}(\rho)}$, dimana $\operatorname{se}(\rho)=$ standar error dari $\gamma$

Kriteria uji :

$H_{0}$ ditolak jika nilai $|t| \geq t_{(n-1, \alpha)}$ atau probabilitas dari $\mathrm{t}<\alpha$

\subsection{Proses Autoregressive Integrated Moving Average atau ARIMA(p,d,q)}

Menurut Wei (2006), proses ARIMA(p,d,q) merupakan model time series yang non stasioner. Bentuk umum model ARIMA $(\mathrm{p}, \mathrm{d}, \mathrm{q})$ adalah:

$$
\phi_{p}(B)(1-B)^{d} Z_{t}=\theta_{q}(B) a_{t}
$$

Dimana $\phi_{p}(B)=1-\phi_{1} B-\phi_{2} B^{2}-\cdots-\phi_{p} B^{p}$ merupakan operator AR yang stasioner dan $\theta_{q}(B)=\left(1-\theta_{1} B-\cdots-\theta_{q} B^{q}\right)$ merupakan operator MA yang invertible. dengan :

$$
\begin{array}{ll}
\mathrm{p} & : \text { orde AR } \\
\mathrm{d} & : \text { orde differencing non musiman } \\
\mathrm{q} & : \text { orde MA } \\
\phi_{1}, \phi_{2}, \ldots, \phi_{p} & : \text { koefisien AR orde } \mathrm{p} \\
\theta_{1}, \theta_{2}, \ldots, \theta_{q} & : \text { koefisien MA orde } \mathrm{q}
\end{array}
$$


$(1-B)^{d} \quad$ : operator differencing orde $\mathrm{d}$

B : operator backshift

$a_{t} \quad$ : residual pada waktu ke-t yang diasumsikan mempunyai rata-rata 0 , varian konstan $\sigma_{a}^{2}$ dan white noise

$Z_{t} \quad$ : variabel respon (terikat) pada waktu $t$

Untuk penduga model ARIMA dapat dilihat menggunakan plot ACF dan PACF, dimana time series berpola stasioner (Soejoeti,1987).

\subsection{Uji Signifikansi Parameter}

Menurut Wei (2006) pengujian parameter AR, MA, dan ARMA dilakukan secara individu pada setiap parameter. Berdasarkan peramaan (2.21) pengujian signifikansi parameter dapat dilakukan sebagai berikut:

1. AR (Autoregressive)

Hipotesis:

$\mathrm{H}_{0}: \phi_{i}=0$ (parameter tidak signifikan terhadap model)

$\mathrm{H}_{1}: \phi_{i} \neq 0$ (parameter signifikan terhadap model)

2. MA (Moving Average)

Hipotesis:

$\mathrm{H}_{0}: \theta_{i}=0$ (parameter tidak signifikan terhadap model)

$\mathrm{H}_{1}: \theta_{i} \neq 0$ (parameter signifikan terhadap model)

Statistik uji :

$$
t=\frac{\widehat{\phi}_{i}}{\operatorname{SE}\left(\widehat{\phi}_{i}\right)} \text { atau } t=\frac{\widehat{\theta}_{j}}{\operatorname{SE}\left(\widehat{\theta}_{j}\right)}
$$

Kriteria uji :

Tolak $\mathrm{H}_{0}$ jika $|t|>t_{\left(\frac{\alpha}{2}: n-p\right)}$ atau p-value $<\alpha$

\subsection{Uji Jarque Bera}

a. Menentukan Hipotesis:

$H_{0} \quad$ : Residual data berdistribusi normal

$H_{1} \quad$ : Residual data tidak berdistribusi normal

b. Taraf Signifikansi:

$\alpha=5 \%$

c. Statistik Uji:

$$
J B=\frac{n}{6}\left(S^{2}+\frac{(K-3)^{2}}{4}\right)
$$

d. Kriteria Pengujian:

Pada taraf signifikansi $\alpha=5 \%$, jika $J B \geq \chi_{1-\alpha, 2}^{2}$ atau $p$-value $<\alpha$, maka $H_{0}$ ditolak yang berarti data tidak berdistribusi normal.

\subsection{Model Autoregressive Integrated Moving Average with Exogenous Variables (ARIMAX)}

ARIMAX adalah model ARIMA dengan faktor eksogen. Dalam model ini faktorfaktor yang mempengaruhi variabel dependen Y pada waktu ke-t tidak hanya oleh fungsi variabel Y dalam waktu (dalam bentuk model deret waktu tertentu, seperti ARIMA atau SARIMA) tetapi juga oleh variabel-variabel independen lain pada waktu ke-t. Menurut Cools (2009), bentuk model ARIMAX (p,d,q) secara umum dapat diberikan dengan persamaan sebagai berikut: 


$$
(1-B)^{d} \phi_{p}(B) Y_{t}=c+\theta_{q}(B) e_{t}+\beta_{1} X_{1, t}+\beta_{2} X_{2, t}+\cdots+\beta_{k} X_{k, t}
$$

dengan

$Y_{t} \quad$ : variabel dependen pada waktu ke-t

$X_{k, t} \quad$ : variabel eksogen ke-k pada saat $\mathrm{t}, \mathrm{k}=1,2, \ldots, \mathrm{k}$

$B \quad$ : operator backshift

c : nilai konstanta

\subsection{Uji Asumsi White Noise}

Menurut Makridakis (1999) untuk memperoleh model peramalan yang baik, residual yang diperoleh dari model yang telah dipilih harus memenuhi proses white noise yaitu residual independen dan varian konstan.

1. Uji Independensi Residual

Uji hipotesis independensi residual dilakukan melalui pengujian Ljung-Box sebagai berikut:

Hipotesis :

$\mathrm{H}_{0}: \rho_{1}=\rho_{2}=\cdots=\rho_{k}=0$ (tidak ada korelasi esidual antar lag)

$\mathrm{H}_{1}$ : minimal ada satu nilai $\rho_{k} \neq 0$ untuk $\mathrm{k}=1,2,3, \ldots, \mathrm{K}$ (ada korelasi residual antar lag)

Statistik uji :

$$
Q^{*}=n(n+2) \sum_{k=1}^{K} \frac{\hat{\rho}_{k}{ }^{2}}{(n-k)}
$$

Statistik Q berdistribusi $\chi^{2}$ dengan derajat bebas (K-m), dimana K adalah lag maksimum dan $\mathrm{m}$ adalah banyaknya parameter pada model atau $\mathrm{m}=\mathrm{p}+\mathrm{q} . \hat{\rho}_{k}{ }^{2}$ adalah autokorelasi dari residual pada lag $\mathrm{k}$.

Kriteria uji :

$\mathrm{H}_{0}$ ditolak jika $\mathrm{Q}>\chi^{2}{ }_{(\alpha ; K-m)}$ atau $\mathrm{P}-$ Value $<\alpha$

2. Uji Kesamaan Varian (Efek ARCH)

Tsay (2005) mengatakan bahwa uji heteroskedastisitas digunakan untuk menguji kehomogenan varian dari residual. Uji Lagrange Multiplier (LM) dapat digunakan untuk mendeteksi adanya proses ARCH/GARCH dengan cara meregresikan kuadrat dari residual model.

Engle (1982) telah mengembangkan uji untuk mengetahui masalah heteroskedastisitas dalam data time series yaitu dengan uji Autoregressive Conditional Heteroscedasticity Lagrange Multiplier (ARCH-LM).

Hipotesis:

$\mathrm{H}_{0}$ : Tidak ada efek ARCH dalam residual (varian tidak bersifat heteroskedastisitas)

$\mathrm{H}_{1}$ : Terdapat efek ARCH dalam residual (varian bersifat heteroskedastisitas)

Statistik uji:

$$
L M=n R^{2}
$$

Dengan $\mathrm{n}$ adalah banyaknya data dan $R^{2}$ adalah koefisien determinasi dalam regresi dari residual kuadrat sampai lag ke-m

Kriteria uji:

Jika $L M>\chi_{p}^{2}{ }_{(\alpha)}$ tolak $\mathrm{H}_{0}$

dengan $\mathrm{p}$ adalah banyaknya variabel independen.

\subsection{Model Autoregressive Conditional Heterosccedasticity (ARCH)}

Model ARCH diperkenalkan pertama kali oleh Engle (1982) untuk memodelkan 
volatilitas residual dan untuk mengatasi variansi error yang tidak konstan dalam data time series finansial. Dalam model $\mathrm{ARCH}$, varian residual data time series tidak hanya dipengaruhi variabel independen, tetapi juga dipengaruhi oleh nilai residual variabel yang diteliti.

Menurut Tsay (2005), lebih spesifikasi lagi, suatu model ARCH orde p diasumsikan bahwa

$$
\begin{aligned}
& \varepsilon_{t}=\sigma_{t} X_{t} \\
& \sigma_{t}^{2}=\alpha_{0}+\alpha_{1} \varepsilon_{t-1}^{2}+\cdots+\alpha_{p} \varepsilon_{t-p}^{2}
\end{aligned}
$$

Dengan $X_{t} \sim$ iid $N\left(\mu, \sigma^{2}\right), \alpha_{0}>0$, dan $\alpha_{i} \geq 0$ untuk $i>0$. Pada kenyataannya $X_{t}$ sering diasumsikan mengikuti distribusi normal baku, maka model $A R C H$ dapat dicirikan dengan $\varepsilon_{t}=\sigma_{t} X_{t}$ dengan $\sigma_{t}$ adalah akar dari variansi bersyarat dalam persamaan (2.34). Model variansi yang memenuhi persamaan $A R C H$ (p) adalah model variansi yang menghubungkan antara variansi error pada waktu ke- $t$ dengan kuadrat error pada waktu sebelumnya.

\subsection{Model Generalized Autoregressive Conditional Heterosccedasticity (GARCH)}

Model ini dikemukakan oleh Bollerslev pada tahun 1986 yang merupakan generalisasi dari model ARCH. Model GARCH digunakan untuk mengatasi orde yang terlalu besar pada model ARCH.

Bentuk umum model GARCH (p,q) menurut Tsay (2005):

$$
\sigma_{t}^{2}=\omega+\sum_{i=1}^{p} \alpha_{i} \varepsilon_{t-i}^{2}+\sum_{j=1}^{q} \beta_{j} \sigma_{t-j}^{2}
$$

$$
\begin{array}{ll}
\text { Dengan } & \\
\sigma_{t}^{2} & =\text { variansi dari residual pada waktu } \mathrm{t} \\
\omega & =\text { komponen konstanta } \\
\alpha_{i} & =\text { parameter dari ARCH } \\
\varepsilon_{t-i}^{2} & =\text { kuadrat dari residual pada waktu } t-i \\
\beta_{j} & =\text { parameter dari GARCH } \\
\sigma_{t-j}^{2} & =\text { variansi dari residual pada saat } t-j
\end{array}
$$

Koefisien-koefisien dari model GARCH $(\mathrm{p}, \mathrm{q})$ bersifat:

(1) $\omega>0$

(2) $\alpha_{i} \geq 0$ untuk $i=1,2, \ldots, p$

(3) $\beta_{j} \geq 0$ untuk $j=1,2, \ldots, q$

(4) $\sum_{i=1}^{p} \sum_{j=1}^{q}\left(\alpha_{i}+\beta_{j}\right)<1$

Kondisi (4) diperlukan agar model bersifat stasioner, sedangkkan kondisi 1,2, dan 3 yang diperlukan agar $\sigma_{t}^{2}>0$ dan untuk penaksiran model GARCH(p,q) dengan orde p dan $\mathrm{q}(\leq 2)$ sudah cukup baik untuk digunakan. (Rosadi, 2012).

\subsection{Uji Efek Asimetris}

Untuk memeriksa keberadaan efek asimetris atau tidak pada data dapat dilakukan uji Sign Bias test (SB test). Uji efek asimetris dilakukan berdasarkan persamaan regresi berikut:

$$
\begin{aligned}
\hat{\varepsilon}_{t}^{2}=\varphi_{0}+\varphi_{1} S_{t-1}^{-}+\varphi_{2} S_{t-1}^{-} \varepsilon_{t-1} & +\varphi_{3} S_{t-1}^{+} \varepsilon_{t-1}+\varepsilon_{t} \\
S_{t-1}^{+} & =1-S_{t-1}^{-1} \\
S_{t-1}^{-} & =\left\{\begin{array}{l}
1 ; \varepsilon_{t-1}<0 \\
0 ; \varepsilon_{t-1} \geq 0
\end{array}\right.
\end{aligned}
$$


Dimana $S_{t-1}^{-}$dan $S_{t-1}^{+}$adalah variable dummy.

Pengujian parameter pada persamaan di atas dilakukan dengan hipotesis berikut:

a. Menentukan Hipotesis:

$\mathrm{H}_{0}: \varphi_{1}=\varphi_{2}=\varphi_{3}=0$ (residual bersifat simetris)

$\mathrm{H}_{1}$ : paling sedikit ada satu $\varphi_{j} \neq 0$, untuk $\mathrm{j}=1,2,3$ (residual bersifat asimetris)

b. Statistik uji:

$$
F_{\text {hitung }}=\frac{S S R_{0} / k}{S S R_{1} / n-k-1}
$$

Dimana $S S R_{0}=\sum_{t=1}^{n}\left(\hat{\varepsilon}_{t}^{2}-\omega\right)^{2}, \omega=\frac{\sum_{t=1}^{n} \varepsilon_{t}^{2}}{n}, S S R_{1}=\sum_{t=1}^{n} u_{t}^{2}, u_{t}^{2}$ adalah residual kuadrat, $\mathrm{n}$ adalah jumlah pengamatan parameter yang diuji.

c. Kriteria uji:

Tolak $\mathrm{H}_{0}$ jika $F_{\text {hitung }}>F_{\text {tabel }}$ atau p-value $<\alpha$.

\subsection{Model TARCH (Threshold Autoregressive Conditional Heterocedasticity)}

Model Threshold Autoregressive Conditional Heterocedastic (TARCH) dikembangkan secara terpisah oleh Zakoian pada tahun 1990, lalu pada tahun 1993 oleh Glosten, Jaganathan dan Rukle. Model ini merupakan pengembangan dari model ARCH dan GARCH. Kelebihan dari model TARCH yaitu model ini mampu mengatasi adanya pengaruh asimetrik, yaitu efek negatif tidak serta merta akan diikuti dengan efek positif dalam ukuran yang sama pada periode berikutnya.

Secara umum, model TARCH dapat ditulis sebagai berikut:

Dimana

$$
\sigma_{t}^{2}=\omega+\sum_{i=1}^{p} \alpha_{i} \varepsilon_{t-i}^{2}+\sum_{j=1}^{q} \beta_{j} \sigma_{t-j}^{2}+\sum_{m=1}^{p} \gamma_{m} \varepsilon_{t-m}^{2} d_{t-m}
$$

$$
d_{t-m}=\left\{\begin{array}{l}
1, \text { jika } \varepsilon_{t}<0 \\
0, j i k a \varepsilon_{t} \geq 0
\end{array}\right.
$$

$\omega>0, \quad \alpha_{i}>0, \quad \beta_{j}>0, \quad$ dan $-1 \leq \gamma_{i} \leq 1$

$i=1,2, \ldots, p$ dan $j=1,2, \ldots, q$

\section{METODOLOGI PENELITIAN}

\subsection{Sumber Data dan Variabel Penelitian}

Jenis data yang digunakan dalam penelitian ini merupakan data sekunder berupa data Indeks Harga Saham Gabungan (IHSG) dan data Kurs Dollar mulai dari bulan Januari 1999 sampai dengan April 2020 yang diperoleh dari web www.yahoo.finance dan investing.com. Variabel dalam penelitian ini terdiri dari variabel respon dan variabel prediktor. Dimana variabel respon $\left(y_{t}\right)$ yang menjadi focus penelitian adalah data IHSG, dengan variabel predictor $\left(x_{t}\right)$ yaitu data Kurs Dollar.

\subsection{Langkah-langkah Analisis}

Tahapan analisis yang dilakukan pada penelitian ini adalah sebagai berikut :

1. Mempersiapkan data yang akan diolah yang terdiri dari variabel independen (IHSG) dan variabel dependen (kurs).

2. Sebelum melakukan pemodelan dengan ARIMAX, terlebih dahulu dilakukan pemodelan dengan ARIMA. Langkah-langkah dalam memodelkan ARIMA sebagai berikut:

a. Melakukan uji stasioneritas data dalam mean dan varian dari data IHSG.

b. Melakukan transformasi jika stasioneritas dalam varian dan dilakukan differencing jika stasioneritas data dalam mean tidak terpenuhi.

c. Melakukan identifikasi model melalui plot ACF dan PACF. 
d. Melakukan estimasi parameter autoregressive (AR) dan moving average (MA) berdasarkan orde yang diperoleh pada tahap identifikasi.

e. Verifikasi model untuk memeriksa model yang telah diestimasi, meliputi uji normalitas, uji signifikansi, dan uji independensi residual.

f. Pemilihan model ARIMA terbaik yang memiliki nilai AIC terkecil.

3. Setelah mendapatkan model ARIMA terbaik, lalu input data Kurs sebagai variabel eksogen ke dalam model ARIMA terbaik untuk memperoleh model ARIMAX.

4. Malakukan uji Independensi untuk model ARIMAX.

5. Melakukan uji Lagrange Multiplier pada model ARIMAX untuk mengetahui apakah terdapat efek heteroskedastisitas pada model.

6. Penaksiran model ARCH/GARCH.

7. Melakukan uji signifikansi pada model ARCH/GARCH dan melihat nilai AIC terkecil untuk menentukan model ARCH/GARCH terbaik.

8. Melakukan uji asimetris untuk mengetahui efek asimetris pada residual data.

9. Jika terdapat efek asimetris, dilakukan penaksiran model TARCH.

10. Evaluasi model yang telah didapatkan dengan menghitung nilai AIC dan memilih model ARIMAX-TARCH terbaik dengan melihat nilai AIC terkecil.

11. Melakukan peramalan dengan model ARIMAX-TARCH.

\section{ANALISIS DAN PEMBAHASAN}

\subsection{Pemodelan ARIMA}

Langkah pertama yang dilakukan dalam pemodelan ARIMA adalah melihat stasioneritas data. Data IHSG belum stasioner dalam varian sehingga dilakukan transformasi dengan $\left(Z_{t}{ }^{0,31}\right)$. Selanjutnya stasioneritas data dalam mean dengan uji Augmented Dickey Fuller (ADF). Berdasarkan uji ADF data IHSG tidak stasioner dalam mean sehingga perlu dilakukan differencing pada lag 1.

Langkah selanjutnya adalah mengidentifikasi model ARIMA dari plot ACF dan PACF data yang sudah stasioner. Setelah dilakukan identifikasi, didapatkan model dugaan sementara yaitu $\operatorname{ARIMA}(1,1,0), \operatorname{ARIMA}(0,1,1)$, dan $\operatorname{ARIMA}(1,1,1)$. Setelah itu dilakukan uji signifikansi parameter, uji independensi, dan uji normalitas untuk menghasilkan model ARIMA terbaik. Pemilihan model terbaik pada model teridentifikasi sebagai berikut:

Tabel 1 Pemilihan Model Terbaik

\begin{tabular}{c|l|l|l|c}
\hline \multicolumn{1}{c|}{ Model } & $\begin{array}{c}\text { Uji } \\
\text { Signifikansi } \\
\text { Parameter }\end{array}$ & $\begin{array}{c}\text { Uji } \\
\text { Normalitas } \\
\text { Residual }\end{array}$ & $\begin{array}{c}\text { Uji } \\
\text { Independensi } \\
\text { Residual }\end{array}$ & Nilai AIC \\
\hline ARIMA(1,1,0) & Signifikan & Tidak normal & $\begin{array}{l}\text { Residual } \\
\text { Inependen }\end{array}$ & $-0,473965$ \\
\hline ARIMA(0,1,1) & Signifikan & Tidak normal & $\begin{array}{l}\text { Residual } \\
\text { Independen }\end{array}$ & $-0,472229$ \\
\hline ARIMA(1,1,1) & $\begin{array}{l}\text { Tidak } \\
\text { Signifikan }\end{array}$ & Tidak normal & $\begin{array}{l}\text { Residul } \\
\text { Independen }\end{array}$ & $-0,468188$ \\
\hline
\end{tabular}

Dari beberapa uji yang telah dilakukan, model terbaik yang didapat adalah model $\operatorname{ARIMA}(1,1,0)$ dengan persamaan :

$$
Z_{t}=\left(1+\emptyset_{1}\right) Z_{t-1}-\emptyset_{1} Z_{t-2}+a_{t}
$$




$$
Z_{t}=1,2203 Z_{t-1}-0,2203 Z_{t-2}+a_{t}
$$

Hal ini dikarenakan model ARIMA(1,1,0) memenuhi syarat signifikansi parameter, syarat independensi residual dan memiliki nilai AIC terkecil.

\subsection{Model ARIMAX}

Model ARIMAX didapat melalui model ARIMA terbaik dengan menambahkan variabel eksogen yaitu data kurs yaitu model ARIMAX $(1,1,0)$, dan berdasarkan lampiran 7. Diperoleh persamaan model ARIMAX sebagai berikut:

$$
\begin{gathered}
Y_{t}=\left(1+\emptyset_{1}\right) Y_{t-1}-\emptyset_{1} Y_{t-2}+122.6381\left(X_{1, t}-X_{1, t-1}\right) \\
Y_{t}=(1+0,1899971) Y_{t-1}-0,1899971 Y_{t-2}-122,6381\left(X_{1, t}-X_{1, t-1}\right) \\
Y_{t}=1,1899971 Y_{t-1}-0,1899971 Y_{t-2}-122,6381 X_{1, t}+122,6381 X_{1, t-1}
\end{gathered}
$$

\subsection{Uji Asumsi White Noise}

\subsubsection{Uji Independensi Residual}

Uji Independensi ARIMAX diperoleh nilai p-value tiap masing-masing lag yaitu $0,6330,785$ dan 0,556 . Jadi, karena p-value $>\alpha=5 \%$ diperoleh hasil bahwa pada model ARIMAX $(1,1,0)$ tidak memiliki korelasi residual antar lag (data independen).

\subsubsection{Uji Kesamaan Varian (Efek ARCH)}

Uji kesamaan varian diperoleh nilai probability sebesar 0,0046 yang mana 0,0046 < $\alpha=5 \%$, sehingga dapat disimpulkan bahwa terdapat efek heteroskedastisitas pada data.

Jadi, dapat disimpulkan bahwa model ARIMAX memenuhi independensi residual tetapi tidak memenuhi uji kesamaan varian yang artinya varian tidak konstan dan terdapat efek heteroskedastis pada residual maka dapat dilanjutkan dengan pemodelan ARCH/GARCH.

\begin{tabular}{|c|c|c|c|c|}
\hline Model & parameter & $\begin{array}{l}\text { Estimasi } \\
\text { parameter }\end{array}$ & p-value & AIC \\
\hline \multirow{2}{*}{$\begin{array}{l}\text { GARCH } \\
(1,0) \\
\text { ARCH(1) }\end{array}$} & $\alpha_{0}$ & 0,020846 & 0,0000 & \multirow[t]{2}{*}{$-0,817517$} \\
\hline & $\alpha_{1}$ & 0,193871 & 0,0199 & \\
\hline \multirow[t]{3}{*}{$\operatorname{GARCH}(1,1)$} & $\omega$ & 0,003867 & 0,1970 & \multirow[t]{3}{*}{$-0,817783$} \\
\hline & $\alpha_{1}$ & 0,126582 & 0,0547 & \\
\hline & $\beta_{1}$ & 0,728316 & 0,0000 & \\
\hline \multirow[t]{4}{*}{ GARCH(1,2) } & $\omega$ & 0,004068 & 0,2293 & \multirow[t]{4}{*}{$-0,810440$} \\
\hline & $\alpha_{1}$ & 0,137686 & 0,0513 & \\
\hline & $\beta_{1}$ & 0,389870 & 0,5151 & \\
\hline & $\beta_{2}$ & 0,318237 & 0,5498 & \\
\hline \multirow{3}{*}{$\begin{array}{l}\text { GARCH } \\
(2,0) \\
\text { ARCH(2) }\end{array}$} & $\alpha_{0}$ & 0,019847 & 0,0000 & \multirow[t]{3}{*}{$-0,810981$} \\
\hline & $\alpha_{1}$ & 0,175936 & 0,0261 & \\
\hline & $\alpha_{2}$ & 0,057019 & 0,5208 & \\
\hline GARCH(2,1) & $\omega$ & 0,001071 & 0,4506 & $-0,812904$ \\
\hline
\end{tabular}

\subsection{Pemodelan ARCH/GARCH}

Penaksiran model ARCH/GARCH diproleh sebagai berikut:

Tabel 2 Penaksiran Model ARCH/GARCH 


\begin{tabular}{l|l|l|l|l}
\hline & $\alpha_{1}$ & 0,164702 & 0,0511 & \multirow{4}{*}{} \\
\cline { 2 - 4 } & $\alpha_{2}$ & $-0,119686$ & 0,2561 & \multirow{4}{*}{0,812912} \\
\cline { 2 - 4 } GARCH(2,2) & $\beta_{1}$ & 0,913420 & 0,0000 & \\
\cline { 2 - 4 } & $\omega$ & 0,015511 & 0,4329 & \\
\cline { 2 - 4 } & $\alpha_{1}$ & 0,173427 & 0,0119 & \\
\cline { 2 - 4 } & $\alpha_{2}$ & $-0,132973$ & 0,2837 & \\
\cline { 2 - 4 } & $\beta_{1}$ & 0,403746 & 0,5001 & \\
\cline { 2 - 4 } & $\beta_{2}$ & $-0,021124$ & 0,9522 & \\
\hline
\end{tabular}

Berdasarkan tabel 4 di atas didapatkan model terbaik dengan parameter yang signifikan (nilai p-value $<5 \%$ ) adalah model GARCH(1,0) atau model ARCH(1) dengan nilai AIC sebesar -0,817517. Diperoleh persamaan model ARCH(1) sebagai berikut:

\subsection{Uji Asimetris}

$$
\sigma_{t}^{2}=0,020846+0,193871 \varepsilon_{t-1}^{2}
$$

Untuk mengetahui apakah terdapat pengaruh asimetris, dilakukan uji sign bias pada data yang telah dimodelkan dalam model ARCH. Hasil uji sign dan size bias pada model ARCH(1) diperoleh nilai Sign Bias sebesar 0,1690 nilai Negative Size Bias sebesar 0,0003 sedangkan nilai Positive Size Bias sebesar 0,8143. Oleh karena terdapat parameter yang signifikan yaitu negative size bias, sehingga dapat disimpulkan model ARCH(1) bersifat asimetris. Karena terdapat efek asimetris pada model ARCH(1) maka dapat dilanjutkan pada model TARCH.

\subsection{Model TARCH}

Hasil dari penaksiran model TARCH ditunjukkan pada Tabel 3

Tabel 3. Penaksiran Model TARCH

\begin{tabular}{l|c|l|l|l}
\hline Model & Parameter & $\begin{array}{l}\text { Estimasi } \\
\text { parameter }\end{array}$ & $p$-value & \multirow{2}{*}{ Aic } \\
\cline { 1 - 4 } TARCH(1,1) & $\omega$ & 0,022001 & 0,0000 & \multirow{2}{*}{$-0,814463$} \\
\hline & $\alpha_{1}$ & 0,050795 & 0,6615 & \\
\hline & $\gamma_{1}$ & 0,212152 & 0,0237 & \\
\hline TARCH(1,2) & $\omega$ & 0,021019 & 0,0000 & \multirow{2}{*}{$-0,819074$} \\
\cline { 1 - 3 } & $\alpha_{1}$ & 0,016314 & 0,0087 & \\
\cline { 1 - 3 } & $\gamma_{1}$ & 0,149465 & 0,0309 & \\
\hline & $\gamma_{2}$ & 0,235528 & 0,0255 & \\
\hline
\end{tabular}

Berdasarkan Tabel 3 di atas, model terbaik dengan semua parameter yang signifikan (nilai $p$-value $<5 \%$ ) adalah model TARCH $(1,2)$ dengan nilai AIC sebesar -0,817517 dengan persamaan model yaitu:

$$
\sigma_{t}^{2}=0,021019+0,016314 \varepsilon_{t-1}^{2}+0,149465 \varepsilon_{t-1}^{2} d_{t-1}+0,235528 \varepsilon_{t-2}^{2} d_{t-2}
$$

\subsection{Peramalan}

Berdasarkan Model ARIMAX-TARCH yang telah diperoleh, didapatkan hasil peramalan IHSG sebagai berikut: 
Tabel 4 Peramalan IHSG dengan Model ARIMAX-TARCH

\begin{tabular}{|l|c|c|}
\hline \multicolumn{1}{|c|}{$\begin{array}{c}\text { Periode } \\
\text { Ramalan }\end{array}$} & $\begin{array}{c}\text { Hasil Ramalan } \\
\text { IHSG }\end{array}$ & $\begin{array}{c}\text { Tranformasi Hasil } \\
\text { Ramalan IHSG }\end{array}$ \\
\hline Mei 2020 & 13,2234 & 4142,27 \\
\hline Juni 2020 & 13,2193 & 4138,08 \\
\hline Juli 2020 & 13,2185 & 4137,29 \\
\hline Agustus 2020 & 13,2183 & 4137,14 \\
\hline September 2020 & 13,2183 & 4137,11 \\
\hline Oktober 2020 & 13,2183 & 4137,10 \\
\hline November 2020 & 13,2183 & 4137,10 \\
\hline Desember 2020 & 13,2183 & 4137,10 \\
\hline Januari 2021 & 13,2183 & 4137,10 \\
\hline Februari 2021 & 13,2183 & 4137,10 \\
\hline Maret 2021 & 13,2183 & 4137,10 \\
\hline April 2021 & 13,2183 & 4137,10 \\
\hline
\end{tabular}

Hasil peramalan menggunakan model ARIMAX $(1,1,0)-\mathrm{TARCH}(1,2)$ memiliki nilai MAPE sebesar $0,141381 \%$. Nilai MAPE yang diperoleh kurang dari $10 \%$ menunjukkan bahwa model dapat digunakan untuk melakukan peramalan dengan sangat baik.

\section{KESIMPULAN}

Berdasarkan analisis yang telah dilakukan, maka dapat diperoleh kesimpulan bahwa model terbaik untuk IHSG bulan Januari 2000 sampai dengan April 2020 adalah model ARIMAX $(1,1,0)$-TARCH(1,2) dan hasil peramalan menggunakan model ARIMAX $(1,1,0)$ TARCH $(1,2)$ memiliki nilai MAPE sebesar $0,141381 \%$. Nilai MAPE yang diperoleh kurang dari $10 \%$ menunjukkan bahwa model dapat digunakan untuk melakukan peramalan dengan sangat baik.

\section{DAFTAR PUSTAKA}

Black, F. (1976). Studies of Stock Price Volatility Changes. Proceedings of the Bussiness and Econometrics Section of the American Statistical Association, 177-181.

Bollerslev. (1986). Generalize Autoregressive Conditional Heteroskedasticity. Journal of Econometric, 307-327.

Brooks, C. (2008). Introductory Econometrics for Finance. New York: Cambridge University Press.

Cools, M., Moons, E., \& Wets, G. (2009). Investigating The Variability In Daily Traffic Counts Using ARIMAX and SARIMA(X) Models. Transportation Research Institute Hasselt University.

Engle, R. F. (1982). Autoregressive Conditional Heteroscedasticity with Estimation of the Variane of United Kingdom Inflation. Econometrica, Vol. 50, 987-1008. 
Hamilton, J. D., \& Susmel, R. (1994). Autoregressive Conditional Heteroskedasticity and Changes in Regimes. Journal of Econometrics, 307-333.

Makridakis, S. d. (1999). Metode dan Aplikasi Peramalan Edisi ke-2. Jakarta: Erlangga.

Permadi, H. d. (2013). Peramalan Saham S\&P 500 Index Menggunakan Model TARCH. Journal Statistik. Universitas Negeri Malang.

Rabemananjara, R., \& Zakoian, J. M. (1993). Threshold ARCH Models and Asymmetries in Volatility. Journal of Applied Econometric, Volume 8.

Rosadi, D. (2012). Ekonometrika dan Analisis Runtun Waktu Terapan dengan EViews. Yogyakarta: C.V Andi Offset.

Thadewald, T., \& Buning, H. (2007). Jarque-Bera test and its competitors for testing normality - A power comparison. Journal of Applied Statistics, volume 34(Issue 1), 87-105.

Tsay, R. S. (2005). Analysis Of Financial Time Series. Chicago: A John Wiley \& Sons, Inc.

Wei, W. W. (1994). Time Series Analysis. America: Department of Statistics Temple University. 